\title{
I feel my wrist buzz. Smartbody and performative sensibility in Fitbit devices
}

\author{
André Luiz Martins Lemos \\ Elias Bitencourt
}

\begin{abstract}
This paper discusses the concepts of performative sensibility and smartbody. The central thesis is that performative sensibility highlights the instrumental nature of sensations in which objects act on the world. We show how the prescriptions of this new sensibility associated with wearables affect the body and subjectivity that we propose to call a smartbody. There were one hundred testimonials analyzed from the oldest thread with the greatest number of comments in the Fitbit user community forum. Quantitative tools and actor-network theory were used as a guide to assemble and analyze the corpus. The preliminary findings show that Fitbit users demonstrate particular changings in body care. Extreme behaviors, physical limits defined by system goals and quantification habits without utilizing the device are some of the examples found. These findings appear to indicate that the performative sensibility of wearables mobilizes new body performatic patterns and practices oriented by data.
\end{abstract}

Keywords: actor-network theory; performative sensibility; smartbody; wearable user experiences; fitbit community.

Resumo: Sinto meu pulso tremer. Smartbody e sensibilidade performativa em dispositivos Fitbit Este artigo discute os conceitos de sensibilidade performativa e corpo inteligente (smartbody). A tese central é que a sensibilidade performativa destaca a natureza instrumental das sensações em que os objetos atuam no mundo. Mostramos como as prescrições desta nova sensibilidade associada aos wearables afetam o corpo e a subjetividade no que propomos chamar de smartbody. Foram analisados cem depoimentos no fórum da comunidade de usuários da Fitbit. As ferramentas quantitativas e a teoria ator-rede foram usadas como guia para reunir e analisar o corpus. Os resultados preliminares mostram que os usuários do Fitbit demonstram mudanças particulares no cuidado do corpo. Os comportamentos extremos, os limites físicos definidos pelos objetivos do sistema e os hábitos de quantificação sem usar o dispositivo são alguns dos exemplos encontrados. Essas descobertas parecem indicar que a sensibilidade performativa dos wearables mobiliza novos padrões performáticos do corpo e novas práticas orientadas por dados. 
Palavras-Chave: Teoria Ator-Rede; sensibilidade performativa; smartbody; tecnologias vestíveis; comunidade Fitbit.

\section{Introduction}

This article seeks to introduce the concept of performative sensibility and its subsequent approximation to bodies (smartbody). It is an exploratory exercise that helps to understand the actions performed by users of Fitbit wearables ${ }^{1}$ in response to orders, prescriptions and instructions from wearable devices and the system that administers these. FitBit is the largest company in this market, of which it has a $25.4 \%$ share, and sold 4.4 million units in the second quarter of $2016^{2}$. The analysis suggests that changes in care of the self (FOUCAULT, 1984) are occurring as a result of physical activities carried out with devices connected to the body that are able to detect movements, collect data, produce instructions and propose rewards. This phenomenon is known as the Internet of Things (IOT) and involves a vast range of objects that have become smart ${ }^{3}$ through digital and algorithmic instrumentalization.

The central thesis of this paper is that digital instrumentalization of objects in the IoT creates possibilities for reacting to the environment and performing actions that we shall call performative sensibility accordingly Blind Review. We show how the prescriptions of this new sensibility associated with wearables affect the individual, modifying his body practices and his view of his own body. This new sensibility associated with objects is performative in Fitbit devices as it demands actions of its users and generates sensations, pleasures and addictions, molding a subjectivity that characterizes what we propose to call a smartbody, a body whose actions and behaviors are guided by the algorithmic prescriptions of a system of objects with performative sensibility.

The research corpus ${ }^{4}$ analyzed here consists of one hundred testimonials from the oldest thread with the greatest number of comments and votes in the Fitbit forum. The methodological procedures and collection tools used were intended primarily to identify matters of concern (LATOUR, 2012) that emerged from the corpus so that the traces and processes associated with the phenomenon could then be observed, documented and described. Quantitative techniques for determining the frequency of keywords in the documents were used together with qualitative analysis of the contexts in which the keywords were found. Once the terms were located within their contexts, excerpts could

1 Personal objects - with onboard computing capacity and an always-on connection to the Internet and to a wide range of other connected objects (the Internet of Things or loT)-attached to the body so that this can produce, store, share and access information autonomously.

2 See: http://www.idc.com/getdoc.jsp?containerld=prUS41718216

3 The term smart (often considered a synonym for intelligent) is used here as a free appropriation of the acronym S.M.A.R.T., meaning Self-monitoring, Analysis and Reporting Technology (ROTHBERG, 2005).

4 The empirical research was carried out by Elias Bitencourt as part of the research for his doctoral thesis, which was in progress at the time of writing. 
be selected and the main debates and issues located. This revealed traces that pointed to a possible emergence of a smartbody.

\section{The internet of things and performative sensibility}

The loT links objects, sensors, activators, networks, technologies, mobile devices, cloud computing, interfaces, apps, algorithms and big data. Estimates by the McKinsey Global Institute suggest that the IOT will have an economic impact of up to USD 11 trillion by 2025. In 2008 there were already more objects than people connected to the Internet. This new revolution has changed the way in which information is produced and distributed (STRIPAS, 2009; DARNTON, 2010; ANDERSON, 2011, Blind Review), the spaces in which narratives are accessed and consumed (GILLESPIE, 2014; VONDERAU, 2015) and economic models (GILLESPIE, 2010; VAIDHYANATHAM, 2011; TURROW, 2012), increasing the tension between the limits of autonomy, freedom and heteronomy (CHENEY-LIPPOLD, 2011; NAFUS; SHERMAN, 2014) and provoking debate about security, surveillance, privacy and governance policies (KITCHIN, 2015; MOROZOV, 2015).

What characterizes loT is digital instrumentalization of objects that have a unique universal identification and autonomously perform tasks and functions, transmitting and receiving data over wireless networks (Wi-Fi, GPRS, Bluetooth, NFC...) and exerting actions on other objects. They generate data from what they capture and process in the environment, allowing them to produce a memory of their actions by storing these data. Analysis of this memory (Big Data) allows projective interventions to be taken to shape the present in real time or the future in the short, medium or long term. Any object can now be instrumentalized in this way, whether it be a physical-first object (such as a paper book) or a digital-first object (such as an e-reader) (GREENGARD, 2015) ${ }^{5}$. Objects therefore start to sense the outside world and the presence of others and to react to the environment in a smart way.

This new sensibility, and the associated innovative form of agency through the action of computerized systems, is performative sensibility (BLIND REVIEW). It provokes actions, carries out orders and commands and is therefore performative in the sense of the performative utterances described by Austin (1962), such as "I hereby declare you husband and wife". For Austin (1962, p. 5-6), "the uttering of the sentence is, or is a part of, the doing of an action [...]". Performative sensibility is therefore the capturing of sensations by objects (an ambient light sensor, for example) and the production of immediate, future and systemic actions (this same sensor, when digitally instrumentalized and communicating over networks, can send commands to turn on or off streetlights, set or turn off night alarms, send usage data to the electricity company, monitor the life of a bulb etc.). The loT is a network of objects that have performative sensibility.

5 Greengard (2015) uses these terms to explain the difference between objects without digital instrumentalization and objects that are created as computerized systems. 
Sensibility is the ability animals have to perceive and act in the (physical or symbolic) environment. The sensations, the information that the senses receive from the outside world, are what the Greeks called aisthesis. They allow the environment to be perceived and action to be taken on it. The sensibility of physical-first objects is reactive compared with other objects in the world (wear and aging, for example). There can be no doubt that automatic mechanical and electronic systems provide objects with a means of sensing the actions of other objects or the environment in a more comprehensive way. This type of independent action and reaction has been evident throughout the history of automation, from clocks in the Middle Ages to robots in modern factories. Automatism has always been a way of expanding the sensibility of objects. This sensibility we understand as a reactive sensibility.

Performative sensibility expands the performance caused by the action of analog automatism. The concept of performative sensibility recognizes that every object has, in one way or another, a life and sensibility (HARMAN, 2011), but that performative sensibility is different from mechanical/analog processes. It is not only reactive, but performative, as it acts so as to provoke systematic changes in a variety of actor-networks ${ }^{6}$. Its performativity is procedural ${ }^{7}$ and dynamic, as pointed out by Manovich (2013) in relation to software performance, and promotes personal data practices according to Lupton (2015a). The term performative sensibility refers not only to the actions performative sensibility produces as a result of the information generated, but also to the performatic way the data are captured, transmitted and stored.

The term performative sensibility seeks to highlight the instrumental character of sensations, an aesthetics of materiality in which objects that are digitally augmented by the loT sense, exchange information, learn and act on the outside world in a performative way only seen in objects instrumentalized in this way. The term SMART, in the sense of Self-Monitoring Analysis and Reporting Technology (ROTHBERG, 2005), can be considered a technical name for this performative sensibility, computational intelligence that processes data and transforms them into information. With regard to smartbodies, the subject of this paper, the performative functions of Fitbit devices produce actions that indicate specific performances for the body to adopt, whether in the physiologic dimension (vibrating and giving orders) or the psychocognitive dimension (producing changes in habits, practices of self and even addictions).

\section{Wearable computing and smartbodies}

Discussions on the technological instrumentalization of the body are not new. However, the popularization of personal computing in the mid-1980s and the growth of

6 A group of important mediators in a given action (LATOUR, 2012).

7 The term procedural is used in the sense in which it is used by Bogost (2007), a form of symbolic expression that uses procedures peculiar to the computing environment rather than the usual processes of representation through written or spoken languages. 
the Internet at the beginning of the 21 st century gave rise to an intense debate about the relationship between bodies and this particular type of technology, resulting in concepts such as the cyborg (HARAWAY, 1985), cybionte (ROSNAY, 1995), hyperbody (LÉVY, 1996), soft self (CLARK, 2003), digitized cyborg assemblage (LUPTON, 2013) and new hybrid beings (THRIFT, 2014). Each of these concepts has in its own way increased the tension in the barriers traditionally established by the mind-body, nature-culture, real-virtual dualism, showing the important role played by computer technologies in reconfiguring the sociabilities, subjectivities and policies of the body.

Nevertheless, although the general idea of a hybrid body instrumentalized by computerized systems is still relevant, the development of network communications protocols (IPV4, IPV6), falling costs of sensors and emergence of ubiquitous computing and the loT have produced new tensions in the body-object-technology association. Wearables are now part of a platform economy, a services model based on an ecosystem of digital media that collect data in exchange for contextualized information and algorithmbased predictions. This new computational sensoriality (performative sensibility) found in wearables, which have gained widespread acceptance, is bringing about some important transformations in body practices and the way the body is perceived.

Targeted at the production of a personalized intelligence based on ostensive biometric monitoring of the body, wearables act not as simple prostheses or extensions of the cyborgbody, but as interpreters of this (LUPTON, 2012). On the one hand, bodies start to be shaped by the properties assigned by the performative sensibilities of the objects attached to them. On the other, the object becomes embodied and integrates human activities into levels to which they did not previously have access. The limits, definitions, institutions and standardizations created to deal with this new body-object construct become the subject of debate, giving rise to new performances of the subject, redefining the fields in which it can act and interact and producing a new subjectivity (body views, practices, symbolisms and uses) or a smartbody.

A new actor-network (LATOUR, 2005) is formed in this body-object-technology relationship, and there is now a device (in the Foucaultian sense of the term) that demands constant attention, that carries out orders and commands, that encourages readings of performance and demands loyalty to a broad information system made up of a network of agents (wearables, equipment, interfaces, apps, access to the Internet, cloud computing, big data...).

Acceptance of the wearables-network implies different types of performativity: continuous use of the device, analysis of the information produced by computer processing and analysis of data, permanent individual monitoring of states of wakefulness and sleep, the need for connection to the Internet and to other devices (such as computers, tablets and smartphones), the construction and checking of current and ideal physical patterns, the management of habits, interference in other bodies and spaces, maintenance and control of the object... In short, the performative sensibility of the wearables-network produces 
this smartbody and, with it, particularities that cannot be reduced to the addition of the technical object to the body and the affordances that can potentially be handled by the human installed (MERLEAU-PONTY, 1999) upon the object.

In addition to these new properties, there is a sharing of the intelligences resulting from human psychocognitive processing and the performative sensibility of the wearable. This connection between the different types of intelligence is not a simple exchange of information. It operates like a cluster ${ }^{8}$ in which distributed processing is shared between the body and the wearable, producing a distributed intelligence that operates translations on both actors in the association. For Merleau-Ponty (1999), the habit of using an object reorganizes and renews the body schema so that the body can perceive the attachments the way it perceives its own hand. Because of habit, the size and volume of objects are no longer determined by comparison with other objects. Instead, objects are transformed into voluminous potentials, sensitive zones perceived by the body in themselves rather than by comparison with other objects.

Consequently, the object and body perceive in relation. It is a knowledge through familiarity with that modulates the body schema and cannot be translated by an objective designation (MERLEAU-PONTY, 1999). It is precisely this condition of digitally instrumentalized corporeality, this sum of voluminous potentials and this associative flux of incorporation and embodiment that we define as smartbody.

\section{Testimonials of a Fitbit community}

Taking into account the theoretical and methodological approach of actor-network theory (LATOUR, 2012), we sought as the empirical object a space in which the body-wearable association could be observed empirically. For this purpose, we chose Fitbit, the largest company in the global wearables market. We then sought to define the corpus using what LATOUR (2012) calls matters of concern, objective agencies that emerge from the network.

The process started with the Fitbit community discussion forum ${ }^{9}$, a space in which users can share habits and practices related to physical activities and well-being. The oldest threads with the greatest number of comments and votes in the forum were selected. In this way, the subjects that most caught users' attention and got community members involved could be identified. According to this criterion, the category Share your Story!, with 29,599 posts, stood out because of the post You know you are a FitBit addict when. The thread was created in December 2013, contained 1,085 replies from 439 participants, was viewed 17,000 times, received a total of 3,981 votes from the community 10 and was still active at the time when the data were collected - March 27th, 2016.

\footnotetext{
8 A term used in high-performance computing to refer to a group of machines that share processing capacity, storage and memory when they are executing tasks.

9 The forum can be accessed at https://community.fitbit.com/t5/Discussions/ct-p/discussions

10 This figure refers to the total of all the votes for each comment in the thread.
} 
A hundred posts were selected from the replies, with priority being given to the fifty most recent and fifty oldest. The comments were then filtered for analysis. Only the first comments by each user were taken into account, and comments by users who posted repeatedly and new users replying to these users were discarded. These measures were intended to eliminate parallel conversations and content that was only marginally related to the main issue. We selected 46 testimonials, of which 26 were from $2013(56.52 \%)$ and $20(43.47 \%)$ from 2016.

Using the Keyword Density tool ${ }^{11}$, the most frequently occurring subjects could be identified so that the analysis could then focus on the contexts in which these subjects appeared. Using this approach, we found that the terms with the highest frequency in all the comments selected for the analysis (excluding articles, prepositions, adverbs, auxiliary verbs, pronouns and numbers) were step(s), addict(ed/ion) and Fitbit, in that order (Fig. 1).

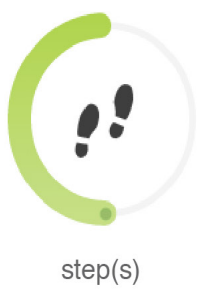

Fig. 1. Most frequently occurring words in all the testimonials, number of comments containing the words and frequency of the words in the dialogs containing the most frequently occurring term. Source: the author.

The word most frequently mentioned by users was chosen to select the comments that would be investigated. Of the 46 comments, 25 mentioned steps in the context of changes in habits, the development of new patterns of behavior, particular ways of appropriating the device, frustrations, physical limitations based on the system's targets and the internalization of procedures for quantifying and valuing addictive behaviors in relation to FitBit activity programs.

The patterns observed in the comments were considered traces of possible translations on bodies and perceptions of self, of the other and of the spaces created from the performative sensibility of the object. To show how important these issues are and the different tensions they produce among the members of the community, eight analysis categories were defined based on the issues that appeared most frequently in the testimonials. These were: change in habit, decontextualized behaviors, forms of appropriation, valuing addiction, frustration with goals, limit defined by system goals, internalization of media procedures and evangelization. After the comments had been

11 The tool is available at http://tools.seobook.com/general/keyword-density/ 
classified, the categories with the greatest number of comments were decontextualized behavior-statements indicating extreme behaviors or behaviors unrelated to the context in order to achieve extra steps; valuing addiction-dialogs that promote addiction to the brand's steps program and devices or that consider addiction to Fitbit as a group identity; limits based on system goals — discussions about the definition of physical limits as they relate to the production of extra steps or the achievement of goals established by the system; and internalization of media procedures - comments that show that counting and ostensive quantification procedures have been incorporated without the device being present on the body and that the system parameters are being used as a reference for observing phenomena, perceiving spaces or the body in space.

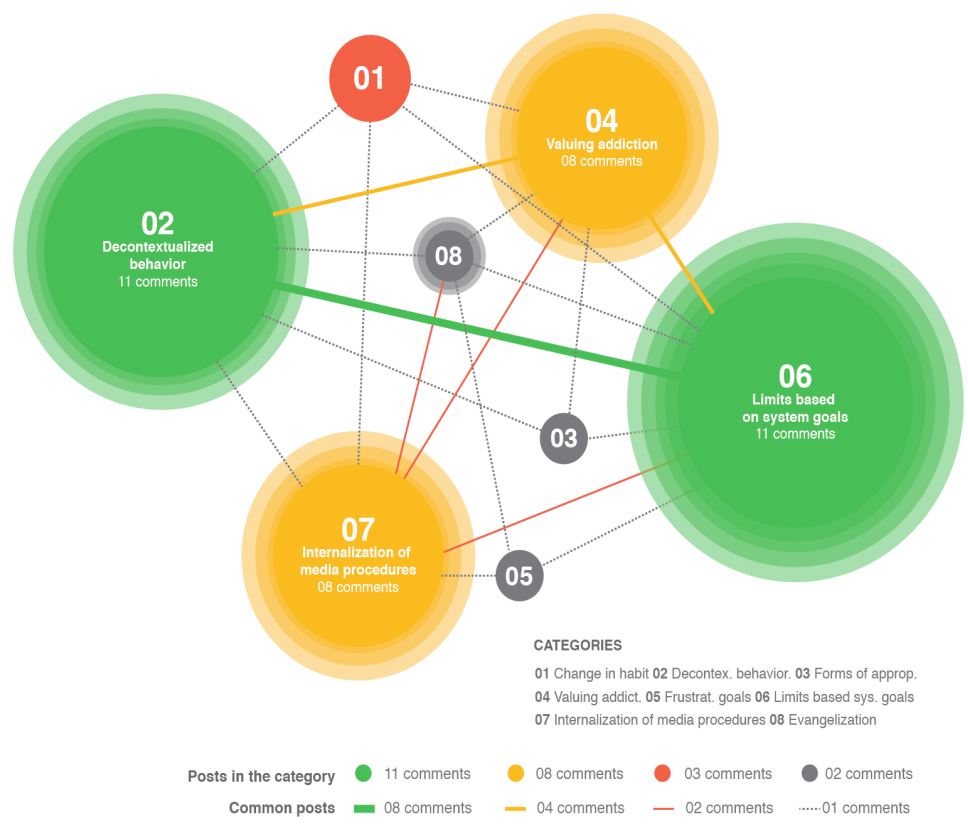

Fig. 2. Connections between the different categories of discourse patterns in the thread in the FitBit community. Source: the author.

The term step(s) is used mainly in posts in which the user acknowledges that he or she is developing decontextualized behaviors with the aim of producing more steps or is establishing personal limits based on system goals_-both categories have the greatest number of comments (eleven in each). This keyword was also found in eight statements that attach importance to or promote behavior indicative of addiction to the device/system and in eight that show that the procedures for constantly monitoring the device have been internalized and are used when the device is not attached to the body. 
In terms of correlation, the category limit based on system goals is the only one that has a relation with all seven other categories. The strongest link this category has is with the category decontextualized behavior (8 of 11 comments appear in this category), followed by valuing addiction (4 of 11 comments also appear in this category) (Fig. 2). The decontextualized behavior class, which, like limit based on system goals, contains eleven testimonials, has its second strongest link with the group of comments that value addiction. In other words, many users who claim to have developed idiosyncratic behaviors in order to achieve more steps also normally use the Fitbit programs to define their own physical limits: "about to go to bed and realize I'm about 100 steps short of 10,000....walk around the house until I feel my wrist buzz" (MIMISC53, 03/03/2016, 11:18h).

Valuing addiction also has a strong relationship with the other two categories mentioned. Of the eight comments in the category, at least four are shared with the two largest groups. This implies that in half the comments that defend Fitbit addiction the device is being allowed to determine the physical limits of the body or the user is participating in decontextualized behaviors. The postures user adopt to engage with wearables and the different ways that information is produced for the system are frequently promoted and lent legitimacy by members of the community.

Hi my name is Mary and I am a Fitbit Addict...... and proud! * You're addicted when you are walking to and fro while waiting for a bus on the bus stop * walking extra steps before going to bed, just to get to your goal * walking around waiting for the water to boil when you want some tea. (MARYKO, 23/03/2016, 07:11 h)

Users not only identify with addictive behaviors (the word addict appears in $44 \%$ of 25 dialogs), but also consider them to be healthy and productive. The terms Fitbit addict and FitBitters always appear in contexts related to the name of the brand or wearable and generally refer to addiction to using the device rather than to the habit of taking regular exercise that the device stimulates. In this sense, addiction is like a label for a set of actions for ostensive monitoring, recording and production of information about the body that are valued as a group identity (LUPTON, 2104a; 2014b; NASCIMENTO, 2014).

These findings appear to indicate that the bodies not only show new performatic patterns mobilized by the performative sensibility of wearables (the decontextualized behaviors and internalizations of media patterns mentioned earlier), but also perform themselves as a condition for the production of data according to the prescriptions of the system. Performative sensibility appears as a property of the wearable devices as well as a quality of the smartbodies that it helps to produce and is therefore an important actant ${ }^{12}$ in the construction of an intelligence about the bodies connected to it. It not only constructs the smartbodies but also embodies itself in them, introjected in behaviors even when the device is not used.

There are many comments that suggest other interactive performances with wearables that go beyond the definition of physical limits based on the system's goals

12 An actant is everything that produces action and can be human or non-human. 
and the development of decontextualized behaviors. These performances indicate that the characteristic agency of the wearable computing environment is incorporated even when the media are not connected to the bodies. Of the 25 comments selected from the corpus, 8 of them illustrate situations in which users internalized the procedures used by the system even when they were not connected to the devices or even incorporated the software metrics as a parameter. These incorporations recursively produce demands for transformations in the devices, for modifications in their algorithmic sensibility and the services offered, for them to adapt to the different forms of appropriation of users and allow an even more immersive engagement in the wearables-network.

The other day, when I was charging my Blaze, I counted my steps as I traveled the office at work. I then got the conversion of steps to miles and added it for the time my Blaze was charging. (ROSEANN_M, 10/03/2016, 16:17h)

There is also a transformation in the way physical activities promoted by the Fitbit action program are signified. In the 25 comments in which the word steps occurs, it is treated as a numerical product of an action and a reward. Walking more, or less, is not reported as a physical gain or loss but as a numerical achievement. The term is frequently associated with the idea of a target to be exceeded using numbers or a reward to be obtained by means of them. In this sense, the term is not merely a measure for quantifying walking or running, but a parameter that is also used to help perceive space ${ }^{13}$, to qualify daily activities or to reformulate them so as to produce steps even when the devices are not connected to the body. In addition, the performative sensibility of the devices is incorporated as a property of the body, which starts to consider sensibility as an infosensitive means of perceiving the world and itself in the absence of the wearable. When users adopt Fitbit system metrics, they qualify behaviors using the metric (steps) and think of space as a condition for producing the data that will expand corporal perception.

Consequently, they start to adopt this instrumentalized sensation as a quality of their own bodies, a smartbody. The system's prescriptions remain present even in the absence of the devices. The procedurality (i.e., the general quality of operating through processes) of the action program of performative sensibility becomes a voluminous potential (MERLEAUPONTY, 1999) of the user's smartbody and part of the repertoire of habits that organizes its body schema (MERLEAU-PONTY, 1992). The connections analyzed (albeit partially) here allow some of the agencies of the performative sensibility of Fitbit wearables to be identified, together with possible translations ${ }^{14}$ operated on the ways users perceive and experience their bodies as smartbodies.

13 Although steps have traditionally been used to measure distances, Fitbit users seem to view everyday spaces in terms of the number of steps they can take. They are not using steps as a means of quantifying distances but as a parameter to engage with the space to improve their interaction with the system.

14 Translation is the transformation produced by an actant, the result of the interests and disputes that are specific to the mediator with which it associates. 


\section{Conclusion}

Performative sensibility is the pillar of algorithmic governmentality (FOUCAULT, 1984) and new practices associated with the development of the loT. It is characteristic of a smart-objects ecology (including plants, humans and other animals). This combination of performative sensibility and a smart-objects ecology has increased the diversity of actors connected to the network of things and expanded the mediatic ecosystem.

We have shown here how this sensibility affects self-practices through the use of Fitbit devices. The changes and transformations observed revolve around routines that appear to undergo translation as the result of a performance geared toward the production of information requested through goals, messages of encouragement and procedures related to the computing environment of the attached devices. The comments collected revealed how the dynamics of the behaviors and performances of the bodies changed so that they interacted with the performative sensibility of the devices. They show particular translations in the different ways of perceiving the body, managing physical activities, exercising care of self and carrying out other daily domestic activities that emerge from this smartbody-wearable association.

Performative sensibility produces action on an extensive system involved in the management of activity. It not only prescribes the bodies with which it connects, but also inscribes itself in them, modifying their algorithms' action programs and refining the sensibilities of devices. It instrumentalizes new forms of sensing and perceiving the world by means of an intelligence built from large quantities of data, a variety of media and computing power. This intelligence produces enhanced perception as well as a performatization of bodies so they constantly produce data. The information generated strains the limits of the autonomy, temporality and materiality of sensation.

Although we acknowledge the need for more comprehensive studies on the particular ways in which the concepts presented here are appropriated, as well as the possibilities for subverting the action programs implicit in the programming of the systems, we would argue that performative sensibility highlights the instrumental nature of sensations and an aesthetics of materiality in which objects act on the external world and perform important translations on it. We have analyzed signs of these transformations in the context of the body and have shown some signs that may point to the emergence of the smartbody, a complex phenomenon that invites further discussions on the politics, aesthetics and ethics of the body in the current digital age.

André Luiz Martins Lemos é professor da Facom/UFBA.

almlemos@gmail.com 
Elias Bitencourt é professor da UNEB e doutorando em Comunicação e Cultura Contemporâneas na FACOM/UFBA. eliasbitencourt@gmail.com

\section{References}

ANDERSON, C. W. Deliberative, agonistic, and algorithmic audiences: Journalism's vision of its public in an age of audience. Journal of Communication, $n^{\circ}$ 5, p. 529-547, 2011.

AUSTIN, J. L. How to Do Things with Words. Oxford: Clarendon Press, 1962

BOGOST, I. Persuasive games: the expressive power of videogames. Mit Press, 2007.

CHENEY-LIPPOLD, J. A new algorithmic identity: Soft biopolitics and the modulation of control."Theory, Culture and Society, $\mathrm{n}^{\circ} 28$, p.164-181, 2011.

CLARK, A. Natural-Born Cyborgs. Minds, Technologies, and the Future of Human Intelligence. New York: Oxford University Press, 2003.

DARNTON, R. A questão dos livros: passado, presente e futuro. São Paulo: Companhia das Letras, 2010.

DESCARTES, R. O discurso do método. São Paulo: Martins Fontes, 2001

ROSNAY, J. L'homme symbiotique. Editions du Seuil, 1995.

FOUCAULT, M. Le Souci de soi. Paris: Gallimard, 1984

GILLESPIE, T. The politics of 'platforms'. New Media and Society, nº 12, p. 1-18, 2010.

. The Relevance of Algorithms. Media technologies: essays on communication, materiality, and society. p. 167, 2014.

GREENGARD, S. The Internet of Things. Cambridge: MIT Press, 2015

HARMAN, G. The quadruple Object. Whashington: Zero Books, 2011

HARAWAY, D. Manifesto for cyborgs: science, technology, and socialist feminism in the 1980s. In: Socialist Review, $\mathrm{n}^{\circ}$ 80, p.65-108, 1985.

KITCHIN, R.; LAURIAULT, T. P.; MCARDLE, G. Knowing and governing cities through urban indicators, city benchmarking and real-time dashboards. Regional Studies, Regional Science, v. 2, n. 1, p. 6-28, 2015.

LATOUR, B. Reagregando o social: uma introdução à teoria Ator-rede. Salvador: Edufba, 2012.

LÉVY, P. O Que é Virtual?. Rio: Editora 34, 1996

LUPTON, D. M-health and health promotion: The digital cyborg and surveillance society. Social Theory \& Health, v. 10, n. 3, p. 229-244, 2012.

The digital cyborg assemblage: Haraway's cyborg theory and the new digital health technologies (preprint). In: COLLYER, F. (ed) (forthcoming), The Handbook of Social Theory for the Sociology of Health and Medicine. Houndmills: Palgrave Macmillan, 2013

You are Your Data: self-Tracking Practices and Concepts of Data. Available at: < http://papers. ssrn.com/sol3/Papers.cfm?abstract_id=2534211 >. Accessed on: 22 Dec. 2015.

Self-tracking cultures: towards a sociology of personal informatics. Proceedings of the 26th 
Australian Computer-Human Interaction Conference on Designing Futures: the Future of Design. New York: ACM, p. 77-86, 2014b.

Personal data practices in the age of lively data. Available at: <http://papers.ssrn.com/sol3/ papers.cfm?abstract_id=2636709>. Accessed on: 10 Jan. 2015.

. Digital Society. New York: Taylor \& Francis, 2015b

MANOVICH, L. Software takes command. New York: Bloomsburry Academic, 2013

MERLEAU-PONTY, M. O visível e o invisível. São Paulo: Perspectiva, 1992.

Fenomenologia da percepção. São Paulo: Martins Fontes, 1999.

MOROZOV, E.; HAAS, P. Le mirage numérique: pour une politic du Big Data. Paris: Les Praires Ordinaires, 2015

NASCIMENTO, L. C. O auto-conhecimento através dos números: as práticas de auto-monitoramento dos quantified selves. Tese (Doutorado). Universidade Federal do Rio de Janeiro, Escola de Comunicação, 2014.

NAFUS, D.; SHERMAN, J. Big Data, Big Questions. This One Does Not Go Up To 11: The Quantified Self Movement as an Alternative Big Data Practice. International Journal of Communication, v. 8 , p. 11, 2014.

STRIPHAS, T. The Late Age of Print: everyday Book Culture from Consumerism to Control. New York: Columbia University Press, 2009.

THRIFT, N. The 'sentient'city and what it may portend. Big Data \& Society, v. 1, n. 1, p. 2053951714532241, 2014. Available at: < THRIFT, Nigel. The 'sentient'city and what it may portend. Big Data \& Society, v. 1, n. 1, p. 2053951714532241, 2014. > Accessed on 10. Mar. 2016.

TUROW, J. The Daily You: how the New Advertising Industry Is Defining Your Identity and Your Worth. New Haven: Yale University Press, 2012.

VAIDHYANATHAN, S. The Googlization of Everything (And Why We Should Worry). Berkeley: University of California Press, 2011.

VONDERAU, P. The Politics of Content Aggregation. Television \& New Media, v. 16, n. 8, p. 717733, 2015. 